\title{
Origin of the concentrated deformation zone in the Japanese Islands and stress accumulation process of intraplate earthquakes
}

\author{
Yoshihisa Iio $^{1}$, Takeshi Sagiya ${ }^{2}$, and Yoji Kobayashi ${ }^{3}$ \\ ${ }^{1}$ Research Center for Earthquake Prediction, Disaster Prevention Research Institute, Kyoto University, Gokasho Uji, Kyoto 611-0011, Japan \\ ${ }^{2}$ Research Center for Seismology, Volcanology and Disaster Mitigation, Nagoya University, Chikusa-ku, Nagoya 464-8602, Japan \\ ${ }^{3}$ Institute for Geoscience, University of Tsukuba, Tsukuba, Ibaragi 305-0006, Japan
}

(Received December 18, 2003; Revised July 13, 2004; Accepted July 13, 2004)

The nature and origin of the concentrated deformation zone along the Japan Sea coast (NKTZ: Niigata-Kobe Tectonic Zone) were clarified by analyzing various observations. We made a qualitative modeling for the stress state and deformation style in and around the NKTZ. In this model a weak zone with low viscosity exists in the lower crust beneath the NKTZ. In the surrounding region, however, the viscosity in the lower crust is very high and can be regarded as elastic for the periods of a recurrence interval of intraplate earthquakes. The concentrated deformation is basically attributed to the low viscosity in the weak zone. In more details, the concentrated deformation is thought to be generated by a postseismic deformation of the weak zone to the previous large intraplate earthquake in the interseismic period (the brittle-ductile interaction model) and/or anelastic deformation in both the upper and lower crusts in the NKTZ, under a finite constant force (the anelastic deformation model).

Key words: Intraplate earthquake, lower crust, anelastic deformation, weak zone, concentrated deformation, NKTZ.

\section{Introduction}

A concentrated deformation zone along the Japan Sea coast (NKTZ: Niigata-Kobe Tectonic Zone) has been detected by dense GPS arrays (GEONET by Geographical Survey Institute), as shown in Fig. 1 (Sagiya et al., 2000). The observed horizontal displacement rates in NKTZ were fitted, quantitatively, by 3 kinematic models named as the detachment model (Hirahara et al., 1998); the collision model (Shimazaki and Zhao, 2000; Heki and Miyazaki, 2001; Miyazaki and Heki, 2001); and the back-slip model (Mazzotti et al., 2000). Iio et al. (2002) examined those models and concluded that they are physically unreasonable since they are all regarded as a collision model in which only the upper crust collides each other. Then, based on the observations that suggested that the lower crust beneath the NKTZ has high water content, Iio et al. (2002) proposed a new model in which a weak zone exists in the lower crust. The model proposed by Iio et al. (2002) is simple. Intuitively, it seems to explain the NKTZ well because a weak zone should deform at a higher strain rate, owing to its low viscosity. However, the new model has not been fully examined quantitatively.

Zoback and Zoback (2002) proposed a simple conceptual model for the intraplate deformation in which the entire lithosphere is in steady-state failure equilibrium under finite plate tectonic forces and high strain rates result from low viscosities in the lower crust and upper mantle. The model proposed by Iio et al. (2002) and Zoback and Zoback (2002) are similar in the aspect that viscosities in the ductile region

Copy right (c) The Society of Geomagnetism and Earth, Planetary and Space Sciences (SGEPSS); The Seismological Society of Japan; The Volcanological Society of Japan; The Geodetic Society of Japan; The Japanese Society for Planetary Sciences; TERRAPUB. control the intraplate deformation, however, the former is a regional scale model, while the latter is in global scale.

The model of Zoback and Zoback (2002) is quantitatively reasonable and offers a physical basis for the model proposed by Iio et al. (2002). However, not only the spatial scales but also the time scales of these two models are quite different, the former treats a geological time scale, while the latter deals with a time scale from years to decades. Furthermore, the former did not consider the effect of occurrence of individual earthquakes on the intraplate deformation implying that stable frictional sliding occurs in the upper crust. On the other hand, what is measured by GPS arrays is a present day deformation and it is influenced by the occurrence of individual earthquakes (Sagiya, 2004).

The observed difference in deformation rate between in and around the NKTZ is almost one order of magnitude (Sagiya et al., 2000). To produce such a significant difference in deformation rate requires an incredibly huge stress concentration in the NKTZ if there is no weak zone with low viscosity in the crust. The weak zone may be located in the upper and/or lower crusts.

If (1) the intraplate lithosphere is subjected to a finite constant force, (2) no intraplate earthquake occurs there, and (3) the upper crust consists of purely elastic materials, no deformation could exist when the intraplate lithosphere reached into an equilibrium stress state, as long as the upper crust, the lower crust and the upper mantle are coupled each other. Consequently, in order to generate deformation, it is necessary to exclude any of these three conditions in a model. In other words, a model should be (1) to subject the intraplate lithosphere under an increasing/decreasing force, (2) to generate a large intraplate earthquake, or (3) to create 


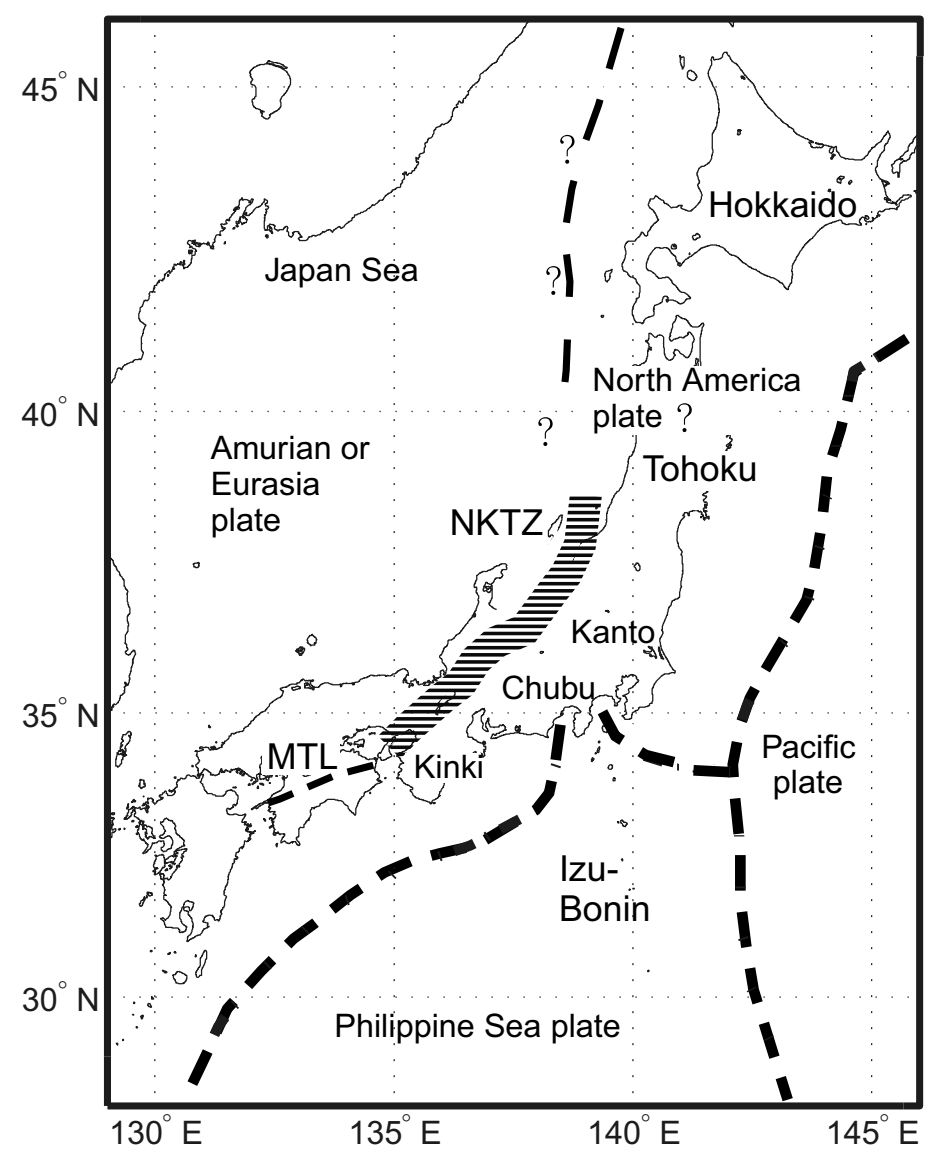

Fig. 1. Map showing plate boundaries in and around the Japanese Islands. The NKTZ (Niigata-Kobe Tectonic Zone) is the concentrated deformation zone along the Japan Sea coast. MTL: Median Tectonic Line (reproduced from Iio et al., 2002).

anelastic deformation in the upper crust.

In this paper, we shall first make a brief review on the previous observation and modeling regarding to NKTZ. Then, we shall discuss three possible models derived from the above three conditions: (1) the velocity boundary condition model, to which we do not apply a constant stress boundary condition but a constant velocity boundary condition at the plate boundary; (2) the brittle-ductile interaction model where postseismic deformation occurs during an interseismic period in the lower crust and/or the upper mantle beneath the earthquake fault because these ductile layers must be shortened when the upper crust was shortened by an earthquake slip; and (3) the anelastic deformation model of which aseismic faulting, as well as anelastic deformation, occurs in the upper crust. And we shall examine these three models based on the observations and analyses relevant to the properties of the weak zone and surrounding region in the lower crust, such as deformation pattern, and the strength in the lower crust and select the most plausible model for the NKTZ.

In this paper, the lower crust means the crust below the seismogenic region.

\section{A Brief Review of the Previous Observation and Modeling on NKTZ}

2.1 Present day deformation in the Japanese Island arc Horizontal velocity vectors in and around the NKTZ are shown in Fig. 2 (Iio et al., 2002). The velocity vectors are computed relative to the Amurian (AMU) plate using the Amurian (AMU)-Eurasian plate pole (Sagiya et al., 2000; Heki et al., 1999). Contours of the horizontal velocities are drawn in a step of $0.5 \mathrm{~cm} / \mathrm{y}$. The largest strain rate was observed between the contours of 1.5 and $2.0 \mathrm{~cm} / \mathrm{y}$ along the axis O-O' in Fig. 2. Sagiya et al. (2000) revealed that in the NKTZ, contraction dominates with no extension.

GEONET produces accurate horizontal ground-velocity data, vertical displacements, however, are not well determined. Since there is no leveling route in high mountain regions in Japan, no vertical ground displacement/velocity data are available in this region.

As a typical example, Figure 3 shows a plot of the ground velocity versus the distance from O-O' for the rectangle area indicated by the thick line in Fig. 2. Iio et al. (2002) showed that the typical velocity profiles could be fitted by 3 kinematic models: the detachment model (Hirahara et al., 1998), collision model (Shimazaki and Zhao, 2000; Miyazaki and Heki, 2001; Heki and Miyazaki, 2001), and back slip model (Nakagawa et al., 2001), indicated by solid, broken, and dotted lines, respectively. The configurations and parameters of these models are shown in Fig. 4 and Table 1. Every model consists of the upper and lower layers, and the boundaries of the upper and lower layers are fixed at a depth of $15 \mathrm{~km}$ in order to fit the observation.

In the detachment model (Fig. 4(a)), the fault plane is horizontal, while the direction of the maximum principal stress also lies horizontally in the intraplate region in the 


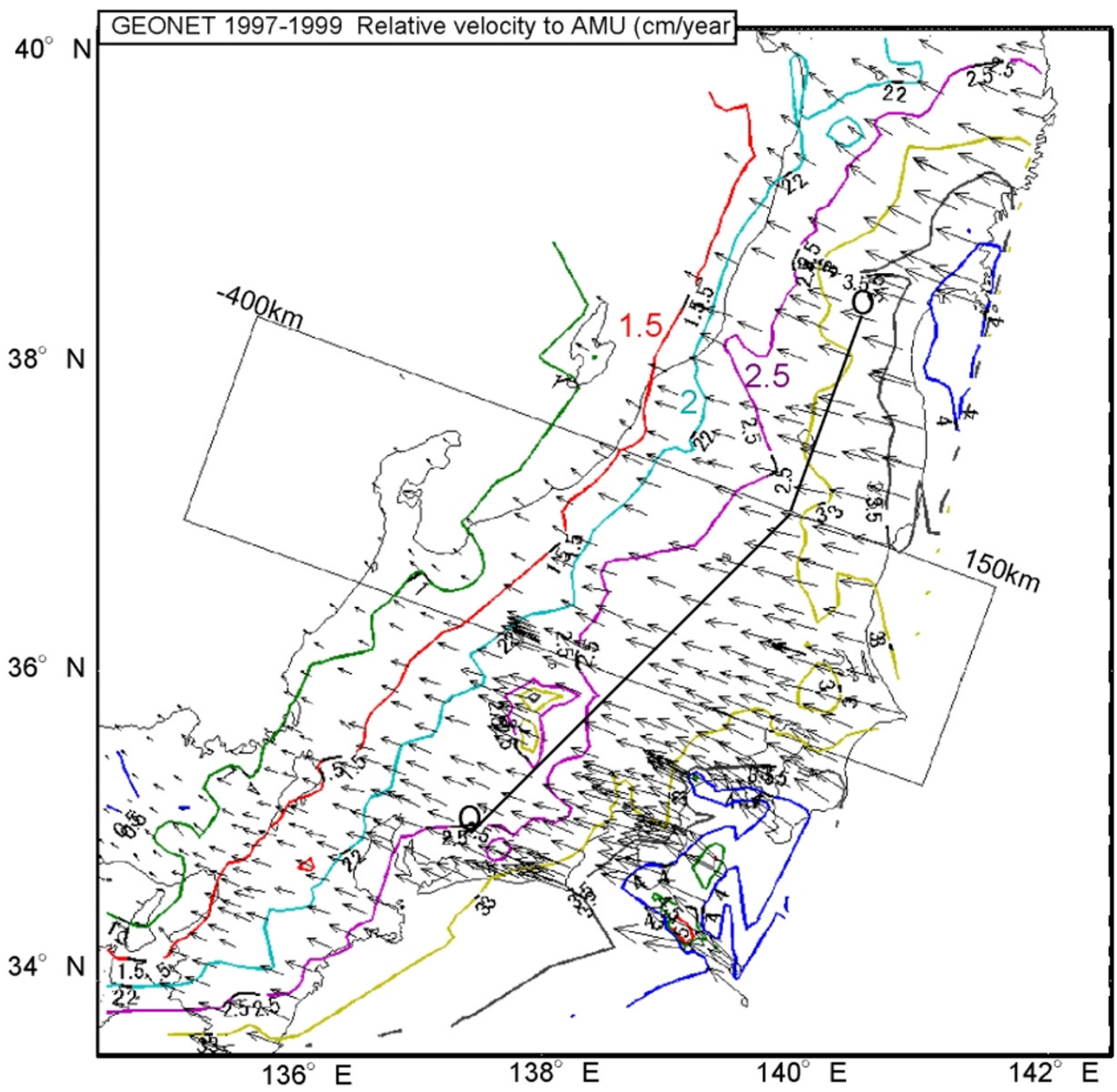

Fig. 2. Horizontal velocity vectors relative to AMU in and around the NKTZ. Contours of the horizontal velocities are displayed in steps of $0.5 \mathrm{~cm} / \mathrm{y}$ (reproduced from Iio et al., 2002).

Table 1. Fault parameters of the three kinematic models used to fit the GPS data. For the back slip and collision models, the parameters of the back slips are shown. The depth indicates the uppermost end of fault planes. Slip directions are misprinted in Iio et al. (2002) and corrected in this table.

\begin{tabular}{lccccccc}
\hline & $\begin{array}{c}\text { Width } \\
\mathrm{km}\end{array}$ & $\begin{array}{c}\text { Depth } \\
\mathrm{km}\end{array}$ & $\begin{array}{c}\text { Azimuth } \\
\text { degree }\end{array}$ & $\begin{array}{c}\text { Slip } \\
\text { degree }\end{array}$ & $\begin{array}{c}\text { Dip } \\
\text { degree }\end{array}$ & $\begin{array}{c}\text { Dislocation } \\
\mathrm{cm} / \mathrm{y}\end{array}$ & $\begin{array}{c}\text { Dilatation } \\
\mathrm{cm} / \mathrm{y}\end{array}$ \\
\hline Detachment & infinite & 15 & 225 & 115 & 0 & 2.5 & 0 \\
Collision & 15 & 15 & 225 & 0 & 90 & 1.1 & 2.3 \\
Backslip & 40 & 15 & 225 & -68 & 30 & 3.2 & 0 \\
\hline
\end{tabular}

Japanese Islands (Iio, 1996a). Thus, the detachment can hardly slip under such a stress state. If the friction of the detachment were ignorable, the detachment could slip due to the pushing to the crust above the detachment by the subducting oceanic plate. In this case, however, the strain is uniformly distributed and no deformation concentration can be created. So, to produce a concentrated deformation zone, heterogeneity is necessary around the end of the detachment in the upper crust.

As for the collision model, the lower crust has to drag the upper crust down at the boundary depth (Fig. 4(b)). This could happen only if the horizontal boundary of the upper and lower layers coincided with the Moho discontinu- ity where the mantle flow could drag the crust (Seno, 1999). However, the $15 \mathrm{~km}$ depth is nearly coincident with the boundary between the upper and lower crusts but not the Moho in the Japanese Island according to Zhao et al. (1992) from a 3-D velocity inversion. Thus, this model is also considered to be physically unreasonable.

The back slip model is equipped with the aseismicslipping fault in the downward extension of the seismogenic fault, as shown in Fig. 4(c). The fault in the downward extension should be dominated by reverse slip but not strike slip, because of the observed contraction dominance in the NKTZ. Because there are several large strike slip faults in and around the NKTZ, a simple back slip model is physi- 


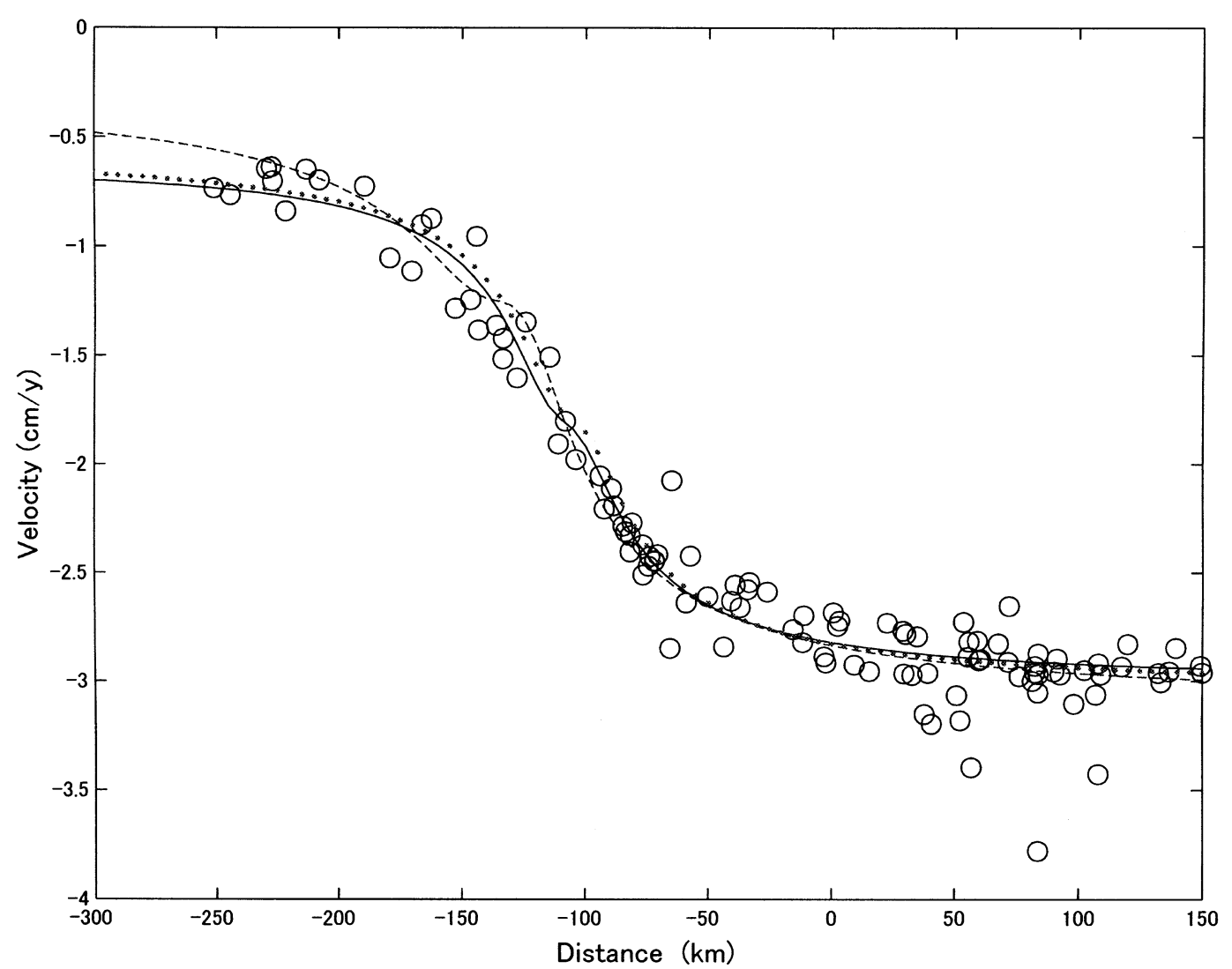

Fig. 3. A typical velocity profile for the rectangle shown in Fig. 2 is fitted by three models: the detachment model (solid line) (Hirahara et al., 1998), collision model (dotted line) (Shimazaki and Zhao, 2000; Miyazaki and Heki, 2001; Heki and Miyazaki, 2001), and back slip model (dashed line) (Nakagawa et al., 2001) (reproduced from Iio et al., 2002).

cally unreasonable.

2.2 Properties of the weak zone and surrounding region

During 1980's, several projects were carried out for magnetic and electric field measurements over northern and central Japan. Based on those observations, Utada (1987) and Utada et al. (1996) revealed the existence of a high conductivity layer in the lower crust beneath the central part of the Chubu district. Iio et al. (2002) pointed out that the geographical distributions of the high conductivity zone, and the ${ }^{3} \mathrm{He} /{ }^{4} \mathrm{He}$ ratio (Sano and Wakita, 1985) are roughly consistent with the NKTZ.

The ${ }^{3} \mathrm{He} /{ }^{4} \mathrm{He}$ ratio is thought to be an indicator of water content in the lower crust, since both ${ }^{3} \mathrm{He}$ and water in the lower crust are considered to come from the upper mantle (Sano and Wakita, 1985; Jones, 1992). The coincidence of the high ${ }^{3} \mathrm{He} /{ }^{4} \mathrm{He}$ ratio and high conductivity suggest that the lower crust beneath the NKTZ is weakened by water. Since it is generally true that plastic flow shows a higher strain rate under wet condition than that under dry condition (e.g., Griggs and Blacic, 1965), the water-weakened lower crust may be the origin of the concentrated deformation.

Based on the above results, Iio et al. (2002) proposed a model (we call it model2002 hereafter) in which the deformation in the lower crust is concentrated in a weak zone with high water content. The high water content is suggested to result from the dehydration of subducting slabs (Iio et al., 2002). Furthermore, the model 2002 proposed that the deformation in the lower crust is not distributed in the whole lower crust but is localized in narrow fault zones, as illustrated in Fig. 4(d). This aspect will be discussed in the next section.

\subsection{Other evidences that support the model2002}

Iio and Kobayashi (2002b) used the high precise deep borehole heat flow measurements to construct the temperature profile from the surface to the depth of $30 \mathrm{~km}$ along Nojima fault where the 1995 Kobe earthquake occurred. Then, they estimated the shear strength profile from the Byerlee's friction law (Byerlee, 1978) and the plastic flow law in the lower crust (e.g., Kohlstedt et al., 1995). They found that the brittle-ductile transition depth is significantly shallower than the depth of the cut-off seismicity under the assumption that the wet granite is deformed at a strain rate of $10^{-15} / \mathrm{s}$ while the depth was accurately determined by hypocentral distribution of the Kobe aftershocks. Such small strain rate implies that the plastic flow is uniformly distributed below the seismogenic zone. However, they found that the cut-off depth could be attributed to the transition depth if the strain rate is greater than $10^{-13} / \mathrm{s}$, indicating that deformation should be localized in a narrow fault zone below the seismogenic zone.

Although this result was obtained only at one fault, the result may be universal in the intraplate region over the Japanese Islands, because the temperature at the cut-off depths in other intraplate regions over Japan are also approximately 600 degree K (Ito, 1990; Kitajima et al., 2001) as seen in the Nojima fault.

Geological surveys of exposed ductile fault zones clearly indicate that deformation in the lower crust is localized in 


\section{a) detachment model}

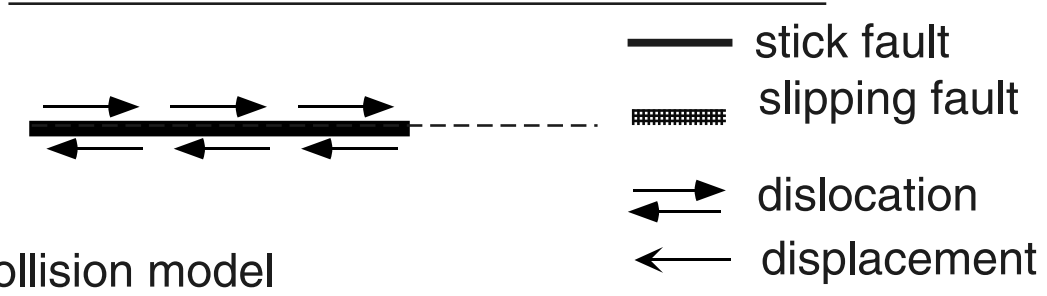

b) collision model $\longleftarrow$ displacement

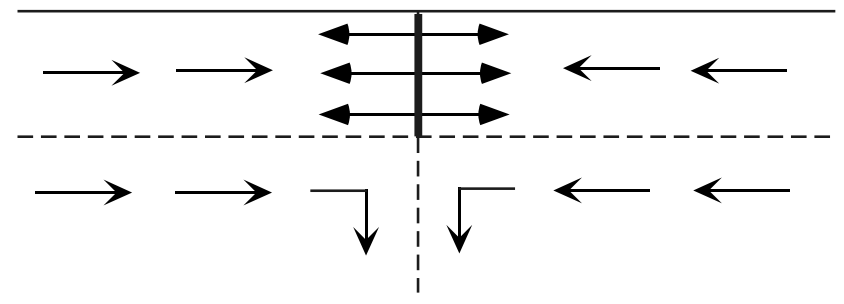

c) back slip model

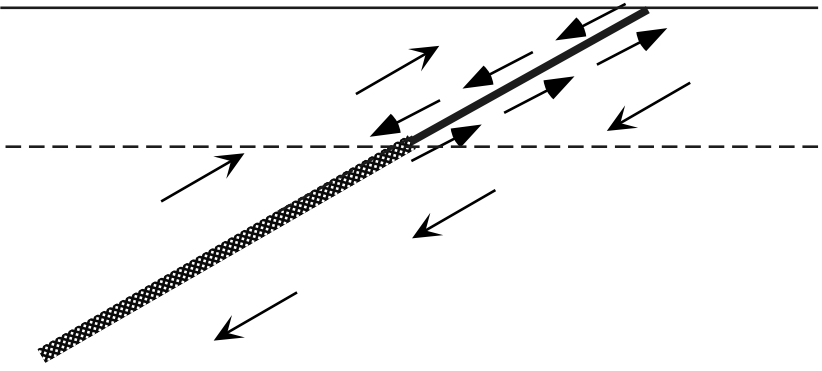

d) model 2002

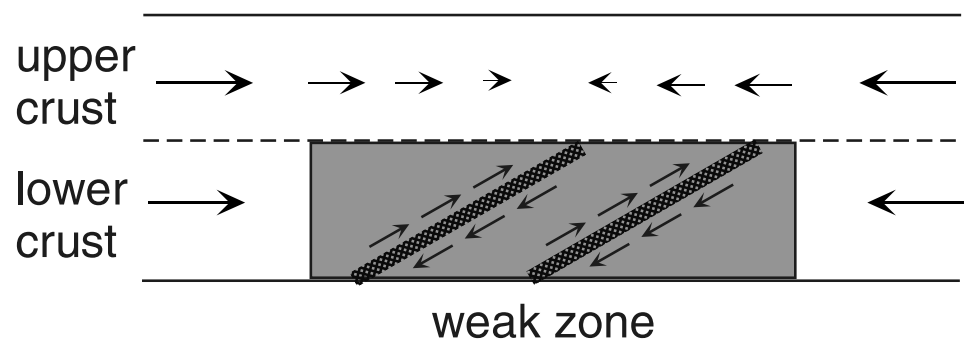

Fig. 4. Configurations of the models that fit the profile shown in Fig. 3: a) the detachment model (Hirahara et al., 1998), b) collision model (Shimazaki and Zhao, 2000; Heki and Miyazaki, 2001; Miyazaki and Heki, 2001), and c) back slip model (Nakagawa et al., 2001). Every model has upper and lower layers, and the boundary of these layers is determined at a depth of $15 \mathrm{~km}$. A new model having a weak zone in the lower crust beneath the NKTZ, d) is also displayed (reproduced from Iio et al., 2002).

narrow fault zones (e.g., Sibson, 1983; Fujimoto et al., 2002; Tomita et al., 2002; Iio and Kobayashi, 2002a). The causes of localization are suggested to be water (e.g., Kronenberg et $a l ., 1990)$ and/or small grain sizes (e.g., Bell and Etherridge, 1973).

From the spatial and temporal correlation of Coda $\mathrm{Q}^{-1}$ and seismicity, Jin and Aki (1989, 1993) and Aki (1995, 1996) proposed the Creep model that suggests the presence of ductile fractures with scale length comparable to the source scale of the characteristic earthquake in a region. More recently, extensive surveys on an exposed ductile fault zone in the Hidaka mountain region in Japan shows that numerous ductile fault zones are distributed below the seismogenic region
(Shimada et al., 2004). It is inferred that the distribution of the fault zones is controlled by pre-existing heterogeneities (Tanaka et al., 2004).

\subsection{Strength in the lower crust}

Strength profile models inferred from plastic flow laws usually predict that the lower crust is weaker than the uppermost mantle (e.g., Kirby and Kronenberg, 1987), assuming that plastic flow is uniformly distributed in the lower crust. However, it is inferred from analyses of reservoirinduced and postseismic deformations that the viscosity in the lower crust is much higher than that in the uppermost mantle (e.g., Kaufmann and Amelung, 2000; Pollitz et al., 2001; Nishimura and Thatcher, 2003). The viscosity can be 


\section{a) Weak zone in the lower crust}

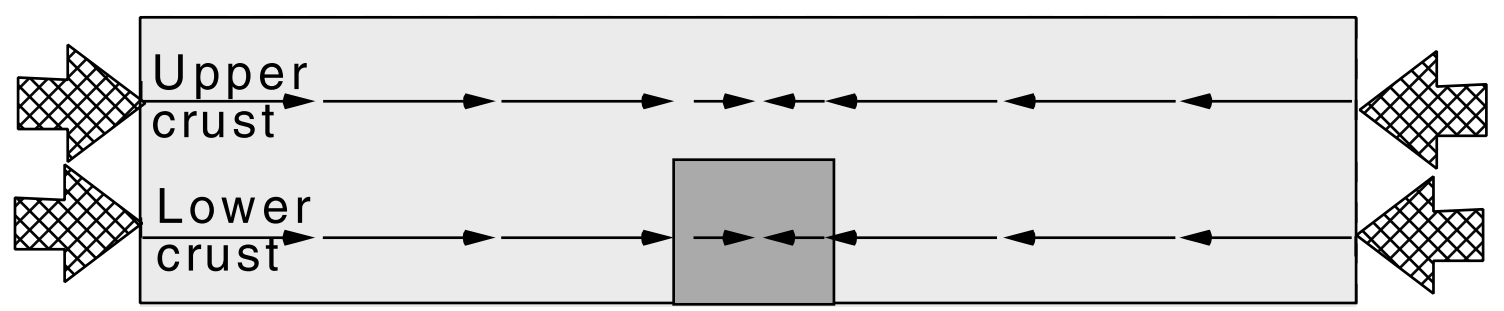

b) Weak zone in the upper crust

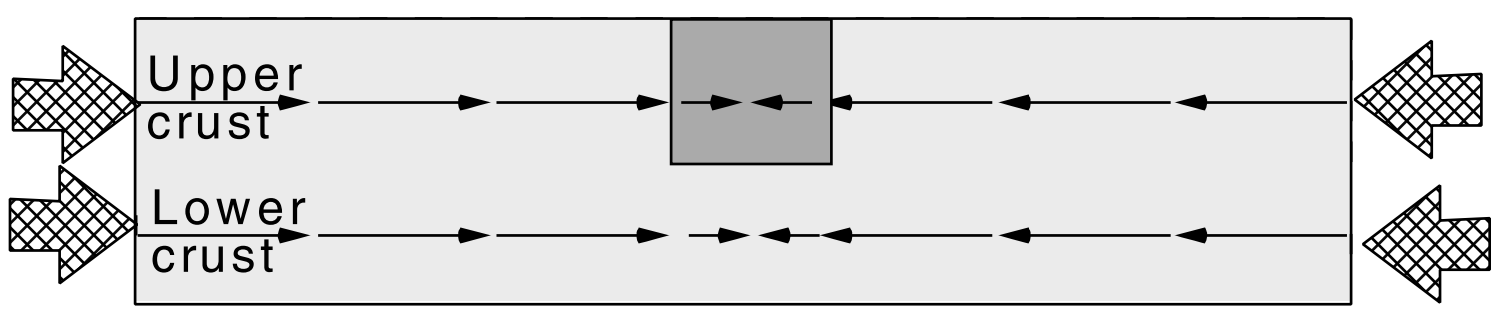

c) Weak zone in the upper and lower crust

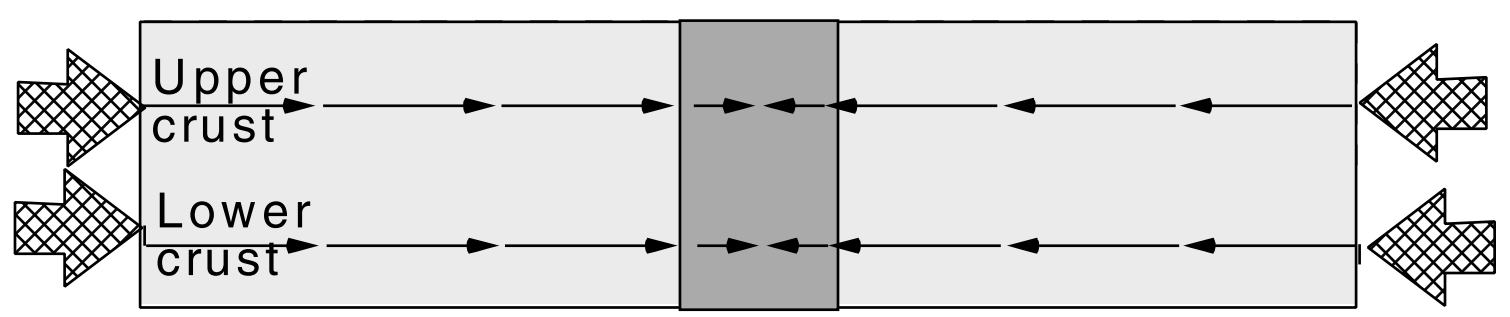

Fig. 5. Possible locations of the weak zone: a) in the lower crust, b) in the upper crust, c) in both the upper and lower crusts. The weak zone is shown by hatched area.

infinite in the intraplate region in the Japanese Islands (Ueda et al., 2003). Since these observations are direct evidences of the viscosity, it is likely that the lower crust is stronger than the uppermost mantle. The high viscosity in the lower crust is possibly because the wet localized weak fault zones deform at a large strain rate, while the dry rocks outside the fault zones have a high strength even at a small strain rate.

Although it is difficult to determine the viscosity in the lower crust accurately, the lower bound of the viscosity is estimated as $10^{20} \mathrm{~Pa}^{*} \mathrm{~s}$ near the Basin and Range province in Nevada, USA (Kaufmann and Amelung, 2000). Then, the relaxation time in the lower crust is estimated to be much longer than hundreds of years. Thus, it is reasonable to assume, according to the results of Kaufmann and Amelung (2000) and Ueda et al. (2003), that the lower crust in the Japanese Islands can be regarded as elastic except for the fault zones, for time period comparable to a recurrence time of intraplate earthquakes. On the other hand, stress relaxation is thought to occur in the uppermost mantle where the viscosity is estimated as $10^{18}-10^{19} \mathrm{~Pa}^{*}$ s (Ueda et al., 2003).

\section{Examination in the Three Models}

Intuitively, the model2002 (Iio et al., 2002) seems to explain the observation well. However, it needs to be detailed with quantitative examinations. Although we already explained in the previous section that the weak zone is most likely located in the lower crust beneath the NKTZ, we shall also examine the possibility that a weak zone exists in the upper crust beneath the NKTZ. There are three possible locations for the weak zone, namely in the lower crust, in the upper crust, or in both the upper and lower crusts, as shown in Fig. 5(a), (b), and (c), respectively. In the lower crust, the 
a)

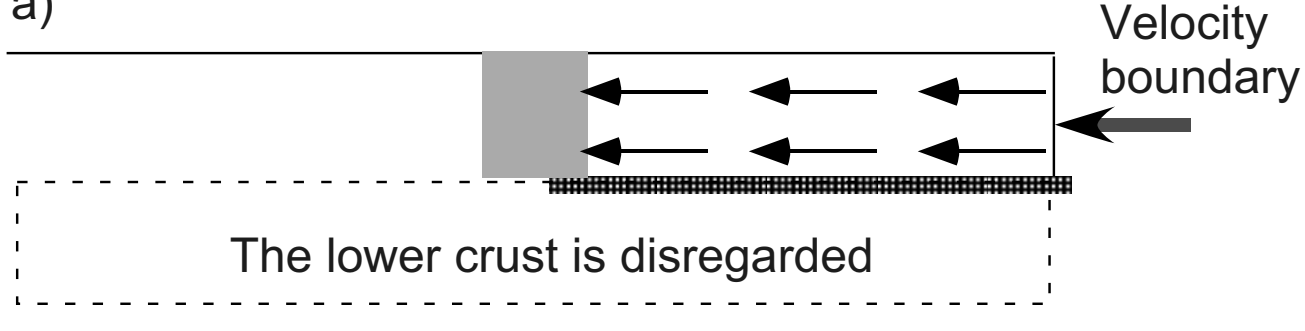

b)

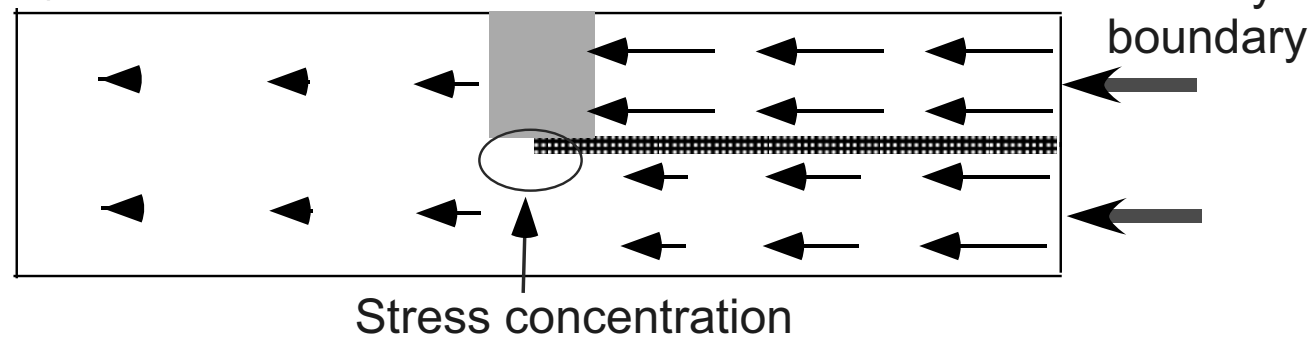

c)
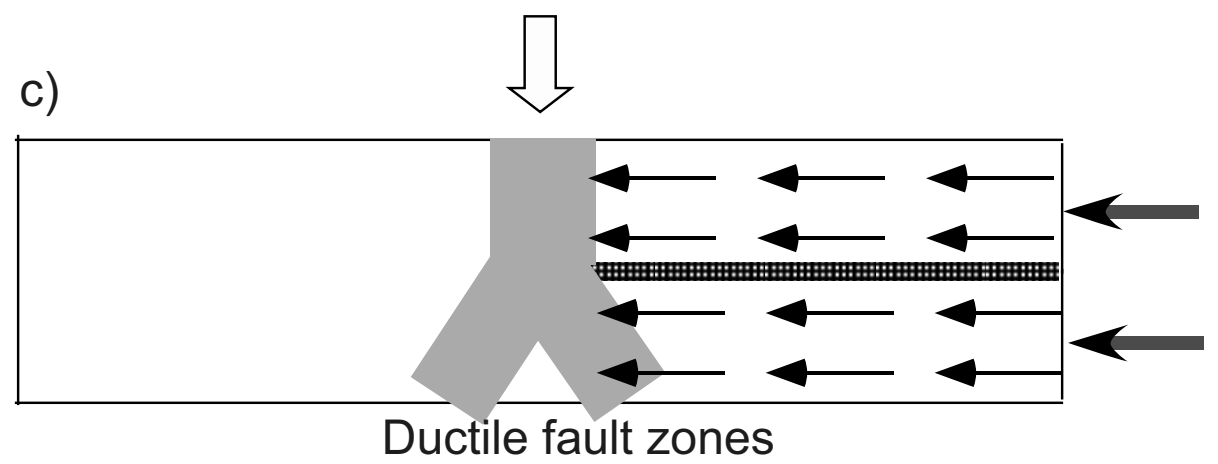

Fig. 6. Schematic illustration showing that the model with a horizontal detachment produces a deformation zone in the lower crust. The model having the weak zone in the upper crust, as a), shifts to that having the weak zone in both the upper and lower crusts, b) to c).

area except for the weak zone is assumed to be elastic. The elastic constants are assumed to be uniform in the crust.

One of the models having the weak zone in the upper crust is the model that the crust above the detachment is pushed by the subducting oceanic (Fig. 6(a)), as discussed before. This model, however, is contradictory to the above assumption that the lower crust except for the weak zone is elastic. Thus, in the following, the lower crust beneath the detachment is assumed to be elastic. If the lower crust is regarded as elastic, the stress concentration should occur at the end of the detachment (Fig. 6(b)). For a long time over several intraplate earthquake cycles, shear zones with ductile nature may be created around the end of the detachment (Fig. 6(c)). Then, this situation is almost the same as the weak zone in both the upper and lower crust (Fig. 5(c)). If the weak zone is in the upper crust without the detachment (Fig. 5(b)), stress concentration occurs in the lower crust below the weak zone and a ductile shear zone would be produced as well. Therefore, the case having the weak zone only in the upper crust (Fig. 5(b)) is equivalent to the weak zone in both the upper and lower crust in a longer time scale. Hence, the case having the weak zone only in the upper crust will not be considered in the following discussion.

\subsection{Stress state in and around the concentrated defor- mation zone}

The three models introduced in the Introduction section are schematically illustrated in Fig. 7. Model 1 is called velocity boundary condition model, in which a velocity boundary condition and a static equilibrium stress state are assumed. In this case, concentrated deformation is generated by the difference in the total strength of the crust between the concentrated deformation zone and the surrounding region, when the horizontal extent of the weak zone is much larger than the thickness of the crust (Hyodo and Hirahara, 2003). In an extreme case, the weak zone in the lower crust is completely relaxed and then can be disregarded. Deformation is concentrated above the weak zone in proportion to the ratio of the thickness of the crust to that of the upper crust.

Model 2 is the brittle-ductile interaction model, for which a constant stress boundary condition is assumed. The concentrated deformation results from a transient postseimic response of the crust to a large intraplate earthquake, as shown in Fig. 8. When an intraplate earthquake occurs, a stress concentration would be generated in the weak zone beneath the earthquake fault. Then, the deformation rate in the weak zone becomes much larger than that in the lower crust except for the weak zone, because of the stress concentration 


\section{Model1}

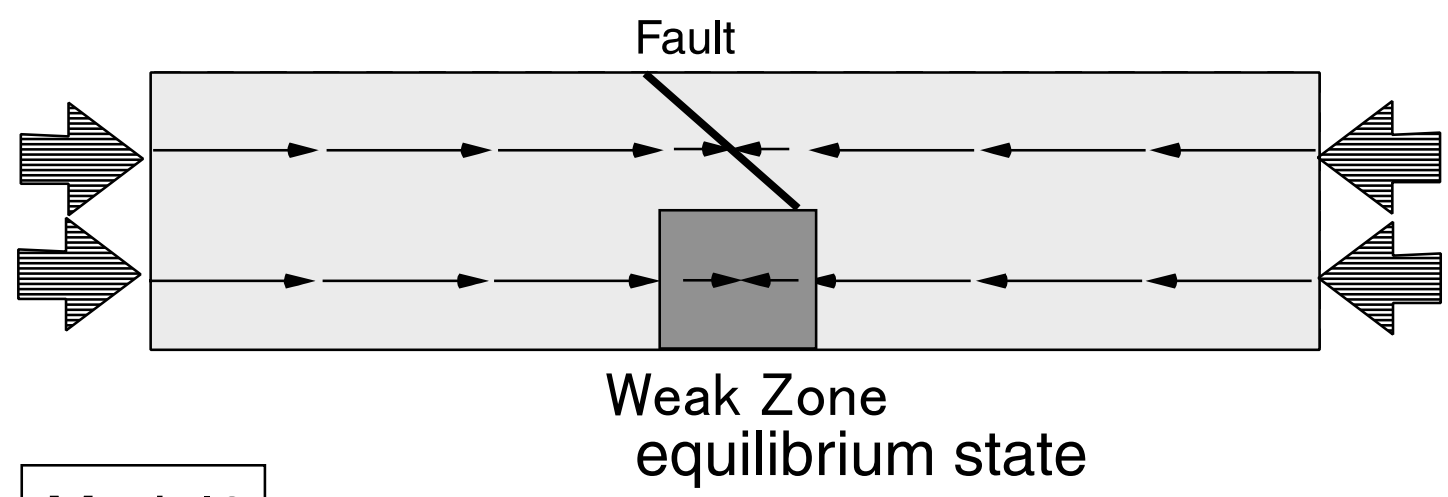

\section{Model2}

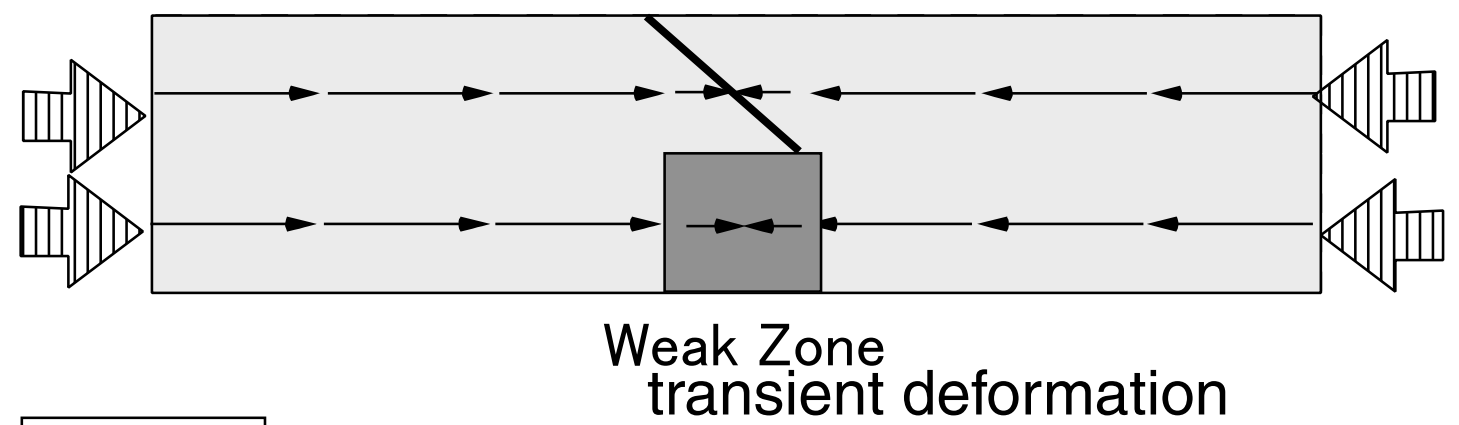

Model3

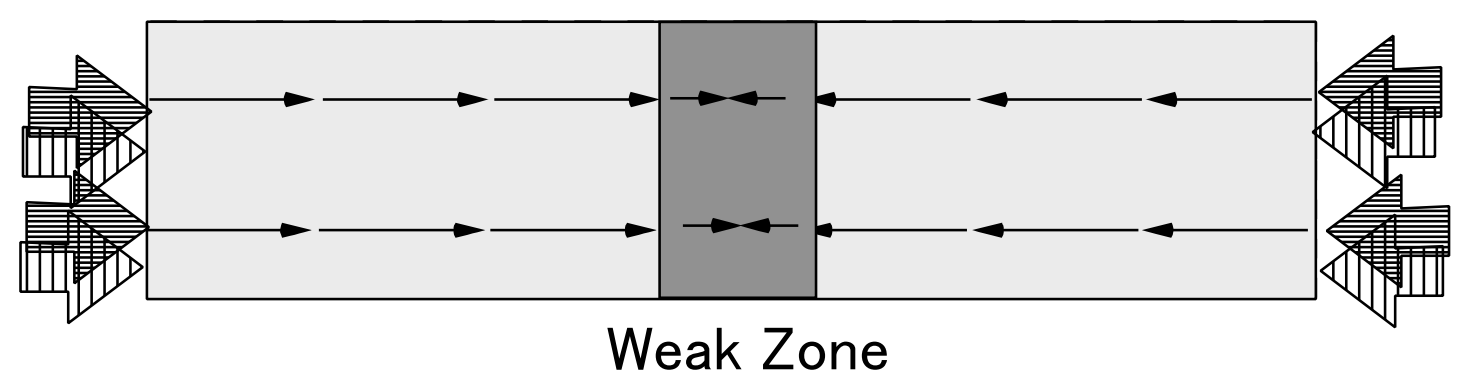

Fig. 7. Three models that may explain the concentrated deformation zone, and their boundary conditions. (1) The velocity boundary condition model: the weak zone in the lower crust with a constant velocity boundary condition. The crust is in equilibrium stress state. (2) The brittle-ductile interaction model: the weak zone in the lower crust with a constant stress boundary condition. The crust shows a postseismic response to large intraplate earthquakes. (3) The anelastic deformation model: the weak zone in the upper and lower crusts.

and its low viscosity. Thus, the concentrated deformation would be generated above the weak zone as long as an equilibrium stress condition has not achieved. Large earthquakes actually occurred in the NKTZ, for example, the 1847 Zenkouji earthquake (M7.4) on the western boundary fault of the Nagano basin, and the 1858 earthquake on the Atotsugawa fault (M7.0-7.1). On the other hand, the surrounding region shows a little deformation under the constant stress condition. Even though an intraplate earthquake could occur in the surrounding region, where a concentrated deformation should not be large due to the higher viscosity (it is assumed to be infinite) in the lower crust comparing to that in the NKTZ.

Model 3 in Fig. 7 is the anelastic deformation model where the weak zone is deformed due to the low viscosity, while the other part is stiff under the constant stress.

The difference between the velocity boundary condition model and the brittle-ductile interaction model is the stress state in the upper crust above the weak zone, as schematically shown in Fig. 9. In the velocity boundary condition model, the stress is concentrated in the upper crust above the weak zone according to the ratio of the thickness of the crust to that of the upper crust. On the other hand, in the brittleductile interaction model, the stress in the upper crust above the weak zone is determined by magnitude of the stress that the weak zone sustains. The stress magnitude is determined by the strength in the weak zone (effective viscosity in the ductile fault zone), the strength of the seismogenic fault, 


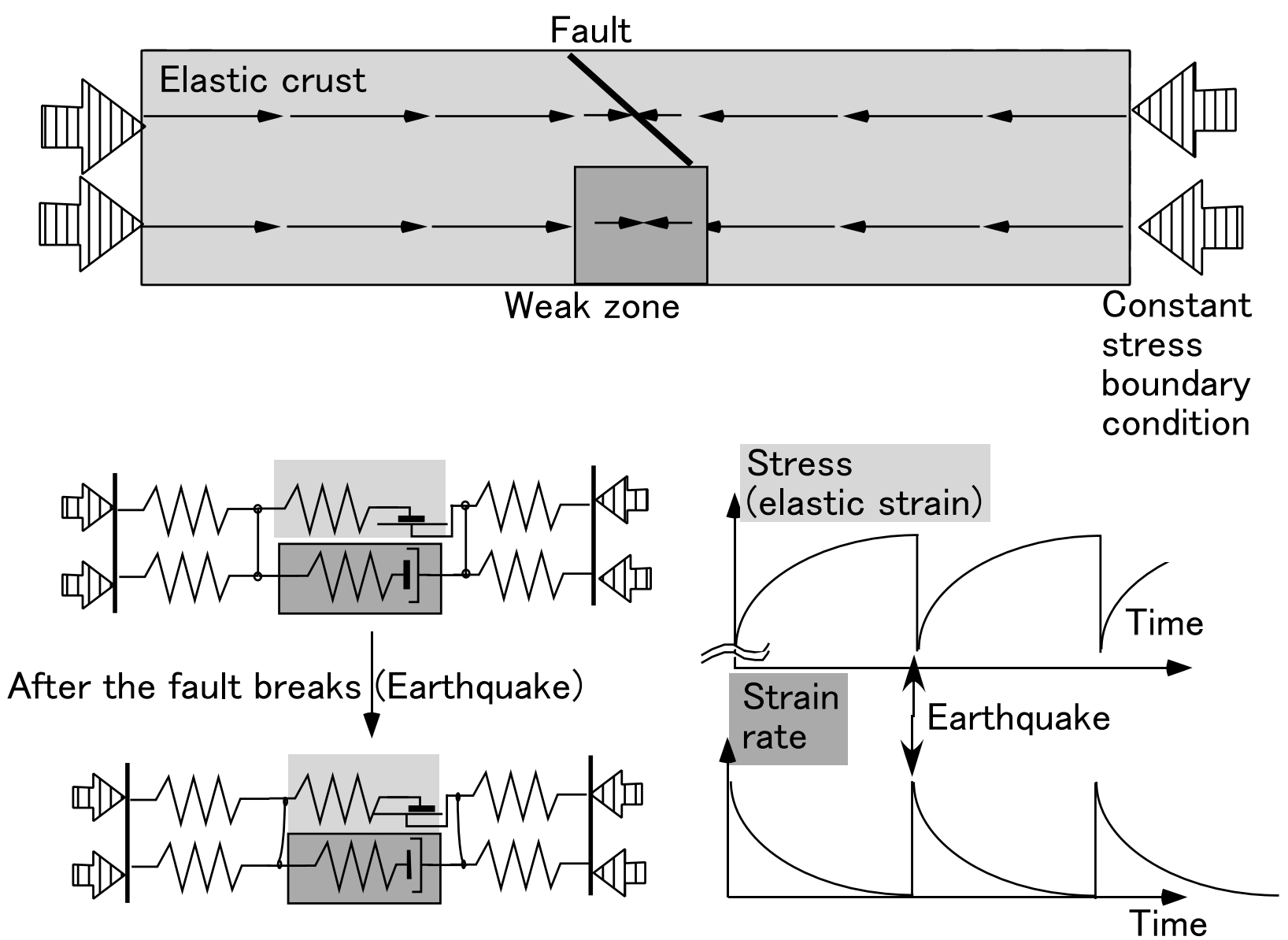

Fig. 8. Detail schematic illustration of the brittle-ductile interaction model (Fig. 7(b)). The concentrated deformation results from a transient postseismic response of the crust to a large intraplate earthquake. In the lower-left panel, the crust is represented by spring-slider-dashpot elements. When the earthquake occurs (the slider slips), the stress concentration is generated in the weak zone (the spring and dashpot are shortened). The time-dependent change in the stress and strain rate in the upper crust above the weak zone is schematically illustrated in the lower-right panel.

and the stress drop of the earthquake previously occurred in the region. Therefore, the stress is not necessarily concentrated in the upper crust. For the velocity boundary condition model, a spatial change in earthquake focal mechanisms would be detected since large stress concentration is predicted by this model. However, observations do not show a tendency that reverse faults events dominate in the concentrated deformation zone (the NKTZ) than in the surrounding area (Fukuyama et al., 2001). Hence, the brittle-ductile interaction model is more presumable than the velocity boundary condition model.

\subsection{Anelastic deformation in the upper crust}

The anelastic deformation model predicts that anelastic deformation occurs even in the upper crust. The GEONET data, actually, suggest this possibility. Sagiya et al. (2000) demonstrated that contraction is dominating in and around the NKTZ while extension is scarcely seen there. However, several strike-slip type faults exist in the NKTZ, for example, the Atotsugawa fault (Research Group for Active Faults of Japan, 1980). Then, as illustrated in Fig. 10, earthquake slips on those strike-slip faults can only release shear strain around the faults but never release contraction. Besides, there is no evidence for active reverse fault that may release the contraction. Therefore, contraction should be continuously released somehow other than earthquake faulting. This implies that anelastic deformation may occur in the upper crust. The inconsistency of the strain rates estimated from geodetic measurements and slip rates of active faults (Wesnousky et al., 1982) may be explained by the anelastic deformation in the upper crust (Iio, 1996b).

Combining the brittle-ductile interaction and anelastic deformation model, the NKTZ can be schematically illustrated in Fig. 11. Ductile faulting with both the strike and reverse components occur in the lower crust. Even in the upper crust, anelastic deformation possibly occurs around the seismogenic faults, since contraction is observed around active faults of strike slip type.

\section{Concluding Remarks}

The nature and origin of the concentrated deformation zone along the Japan Sea coast (NKTZ: Niigata-Kobe Tectonic Zone) were clarified by analyzing various observations and qualitatively modeling the stress state and deformation style in and around the NKTZ.

It is inferred that there is a weak zone with low viscosity in the lower crust in the NKTZ. In the surrounding region, however, the viscosity in the lower crust is very high and may be regarded as elastic for the periods of the recurrence interval of intraplate earthquakes. The concentrated deformation is basically attributed to the low viscosity in the weak zone. 


\section{Averaged differential} stress in the upper crust
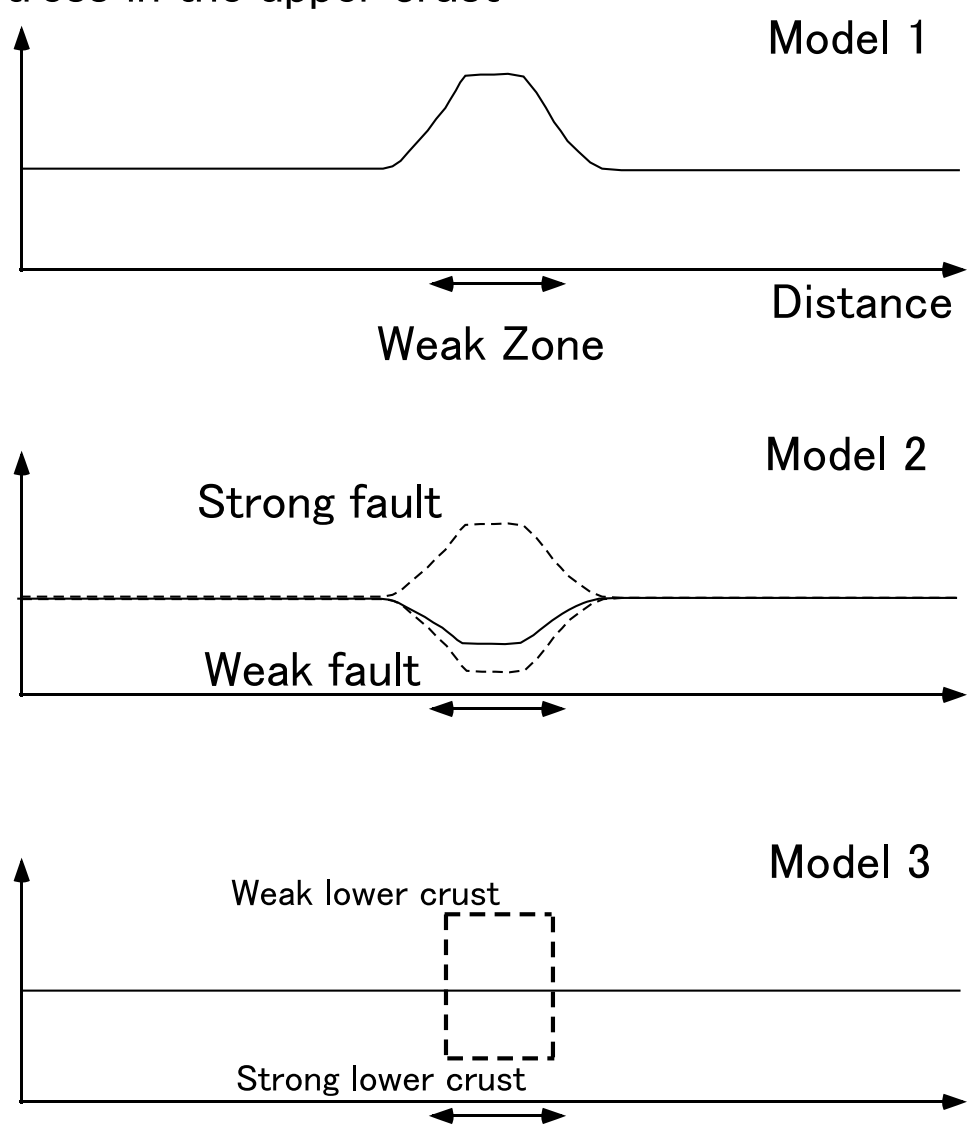

Fig. 9. Schematic illustration showing the stress state averaged in the upper crust in and around the concentrated deformation zone. The difference between the velocity boundary condition model (model 1) and the brittle-ductile interaction model (model 2) is the stress in the upper crust above the weak zone. In the brittle-ductile interaction model, the stress in the upper crust can take an arbitrary value as shown by dashed lines.

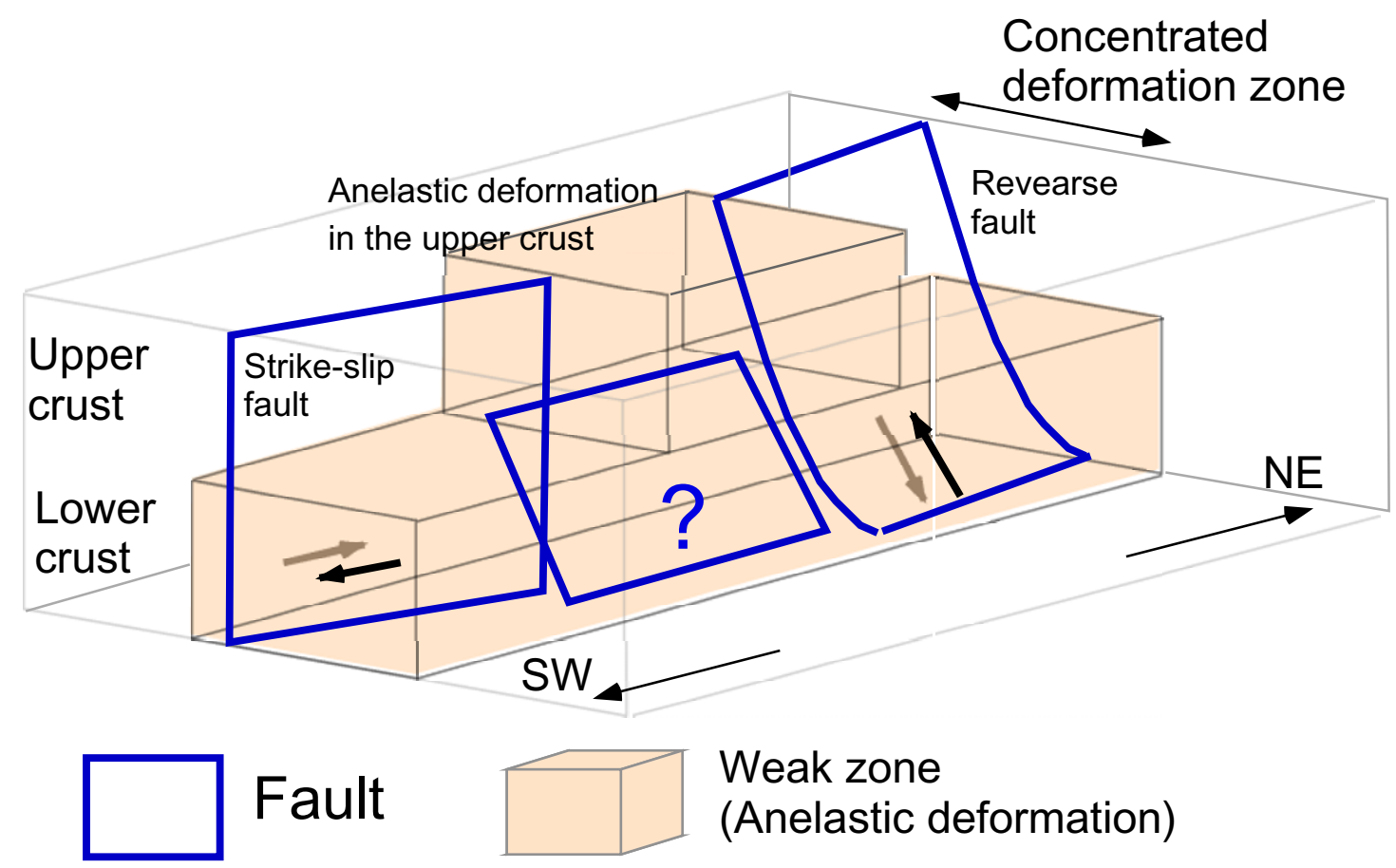

Fig. 10. Schematic illustration showing the difference between the observed horizontal strain rate and the strain that can be released by a large strike-slip earthquake. 


\section{Horizontal crustal
strain observed by \\ Horizontal crustal
strain observed by GEONET}

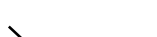

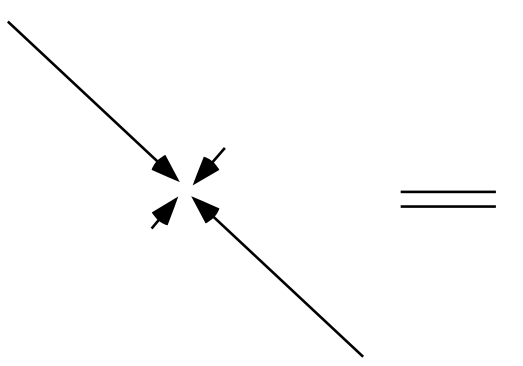

Contraction

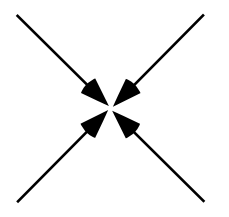

Shear strain

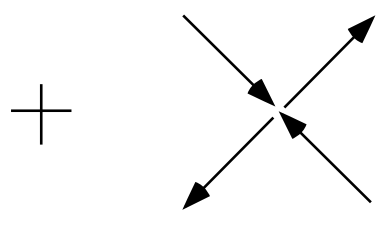

Fig. 11. A 3D schematic model of the concentrated deformation zone, the NKTZ.

In more details, the concentrated deformation is thought to be generated by a postseismic deformation of the weak zone to the previous large intraplate earthquake in the interseismic period (the brittle-ductile interaction model), and/or anelastic deformation in both the upper and lower crusts in the NKTZ, under a finite constant force (the anelastic deformation model).

Although the model presented in this paper is still qualitative, it may present a new point of view on the deformation process in the intraplate region and forecasting intraplate earthquakes.

Acknowledgments. This study is partly supported by a grant from the Comprehensive Joint Research of the Special Coordination Funds for Promoting Science and Technology, entitled "Comprehensive joint research on the modeling of the slip process of earthquake source faults and ductile flow below the seismogenic region". The authors are grateful for Keiiti Aki for his thoughtful review and valuable suggestions. We also thank guest editor, Anshu Jin for her valuable suggestions.

\section{References}

Aki, K., Interrelation between fault zone structures and earthquake processes, Pure Appl. Geophys., 145, 647-676, 1995.

Aki, K., Scale dependence in earthquake phenomena and its relevance to earthquake prediction, Proc. Nat. Acad. Sci. USA, 93, 3740-3747, 1996.

Bell, T. H. and M. A. Etherridge, Microstructure of mylonite and their descriptive terminology, Lithos, 6, 337-348, 1973.

Byerlee, J. D., Friction of rocks, Pure and Appl. Geophys., 116, 615-626, 1978.

Fukuyama, E., A. Kubo, H. Kawai, and K. Nomura, Seismic remote monitoring of stress field, Earth Planets Space, 53, 1021-1026, 2001.

Griggs, D. T. and J. D. Blacic, Quartz-anomalous weakness of synthetic crystals, Science, 147, 292-295, 1965.

Heki, K. and S. Miyazaki, Plate convergence and long-term crustal deformation, Geophys. Res. Lett., 28, 2313-2316, 2001.

Heki, K., S. Miyazaki, H. Takahashi, et al., AMU motion and current plate kinematics in the eastern Asia, J. Geophys. Res., 104, 29147-29155, 1999.

Hirahara, K., M. Ando, Y. Hoso, Y. Wada, and T. Nakano, Search for the movement of an active fault by GPS measurements, Earth Monthly, 225, 149-153, 1998 (in Japanese).

Hyodo, M. and K. Hirahara, A viscoelastic model of interseismic strain concentration in Niigata-Kobe Tectonic Zone of central Japan, Earth Planets Space, 55, 667-675, 2003.

Iio, Y., Depth-dependent change in the focal mechanisms of shallow earthquakes in a seismogenic region: Implications for the brittle-plastic transition, J. Geophys. Res., 101, 11209-11216, 1996a.

Iio, Y., A possible generating process of the 1995 Southern Hyogo prefecture earthquake-stick of fault and slip on detachment-, Zisin 2, 49, 103-112, $1996 \mathrm{~b}$.
Iio, Y. and Y. Kobayashi, A physical understanding of large intraplate earthquakes, Earth Planets Space, 54, 1001-1004, 2002 a.

Iio, Y. and Y. Kobayashi, Is the plastic flow uniformly distributed below the seismogenic region?, Earth Planets Space, 54, 1085-1090, 2002b.

Iio, Y., T. Sagiya, Y. Kobayashi, and I. Shiozaki, Water-weakened lower crust and its role in the concentrated deformation in the Japanese Islands, Earth Planet. Sci. Lett., 203, 245-253, 2002.

Ito, K., Regional variations of the cutoff depth of seismicity in the crust and their relation to heat flow and large inland-earthquakes, J. Phys. Earth, 38, 223-250, 1990.

Jin, A. and K. Aki, Spatial and temporal correlation between coda Q-1 and seismicity and its physical mechanism, J. Geophys. Res., 94, 1404114059, 1989.

Jin, A. and K. Aki, Temporal correlation between coda Q-1 and seismicityevidence for a structural unit in the brittle-ductile transition zone, $J$. Geodynamics, 17, 95-120, 1993.

Jones, A. G., Electrical conductivity of the continental lower crust, in Continental Lower Crust, edited by M. Fountain, R. Arculus, and R. W. Kay, Elsevier, pp. 81-143, 1992.

Kaufmann, G. and F. Amelung, Reservior-induced deformation and continental rheology in vicinity of Lake Mead, Nevada, J. Geophys. Res., 105, 16341-16358, 2000.

Kitajima, T, Y. Kobayashi, R. Ikeda, Y. Iio, and K. Omura, Terrestrial heat flow in Hirabayashi, Awaji, Island, Island Arc, 10, 318-325, 2001.

Kohlstedt, D. L., B. Evans, and S. J. Mackwell, Strength of the lithosphere: Constraints imposed by laboratory experiments, J. Geophys. Res., 100, 17,587-17,602, 1995.

Kronenberg, A. K., P. Segall, and G. H. Wolf, Hydrolytic weakening and penetrative deformation within a natural shear zone, in The Brittle-ductile Transition in Rocks (The heard volume), edited by A. G. Duba, W. B. Durham, J. W. Handin, and H. F. Wang, Am. Geophys. Union, Geophys. Monogr., 56, 21-36, 1990.

Mazzotti, S., X. Le Pichon, and P. Henry, Full interseismic locking of the Nankai and Japan-west Kurile subduction zones: An analysis of uniform elastic strain accumulation in Japan constrained by permanent GPS, $J$. Geophys. Res., 105, 13159-13177, 2000.

Miyazaki, S. and K. Heki, Crustal velocity field of southwest Japan: Subduction and arc-arc collision, J. Geophys. Res., 106, 4305-4326, 2001.

Nakagawa, Y., I. Kawasaki, and Y. Ishizaki, A model of steady state faulting at depths for GPS surface displacements and the stress field in the Hida mountains in the Chubu district, central Honshu, Japan, Bull. Earthq. Res. Inst., 76, 135-143, 2001.

Nishimura, T. and W. Thatcher, Rheology of the lithosphere inferred from postseismic uplift following the 1959 Hebgen Lake earthquake, J. Geophys. Res., 108, 2389, doi:10.1029/2002JB002191, 2003.

Research Group for Active Faults of Japan, Active faults in Japan, sheet maps and inventories, Univ. of Tokyo Press, Tokyo, 1980.

Sagiya, T., A decade of GEONET: 1994-2003-The continuous GPS observation in Japan and its impact on earthquake studies, Earth Planets Space, 56, this issue, xxix-xli, 2004.

Sagiya, T., S. Miyazaki, and T. Tada, Continuous GPS array and present-day crustal deformation of Japan, Pageoph, 157, 2303-2322, 2000.

Sano, O. and H. Wakita, Geographical distribution of ${ }^{3} \mathrm{He} /{ }^{4} \mathrm{He}$ ratios in Japan: Implications for arc tectonics and incipient magmatism, J. Geophys. Res., 88, 8729-8741, 1985. 
Seno, T., Syntheses of the regional stress fields of the Japanese Islands, The Island Arc, 8, 66-79, 1999.

Shimada, K., H. Tanaka, T. Toyoshima, T. Obara, and T. Niizato, Occurrence of strain localized mylonite zones and its implication for seismogenesis at the bottom of upper crust: an example from southern Hidaka Metamorphic Belt, Hokkaido, Japan, Earth Planets Space, 2004 (submitted).

Shimazaki, K. and Y. Zhao, Dislocation model for strain accumulation in a plate collision zone, Earth Planets Space, 52, 1091-1094, 2000.

Ueda, H., M. Ohtake, and H. Sato, Postseismic crustal deformation following the 1993 Hokkaido Nansei-oki earthquake, northern Japan: Evidence for a low-viscosity zone in the uppermost mantle, J. Geophys. Res., 108, No. B310.1029/2002JB002067, 2003.

Tanaka, H., K. Shimada, T. Toyoshima, T. Obara, and T. Niizato, Origin of the strain localization and its implication for seismogenesis at the bottom of upper crust, Earth Planets Space, 2004 (submitted).

Utada, H., A direct inversion method for 2 dimensional modeling in the geomagnetic induction problem, PHD Thesis of Earthquake Res. Inst., the University of Tokyo, 1987.
Utada, H., Y. Hamano, and J. Segawa, Conductivity anomaly around the Japanese islands, Geology and Geophysics of the Japan Sea (Japan-USSR Monograph Series, 1), pp. 103-149, 1996.

Wesnousky, S. G., C. H. Scholz, and K. Shimazaki, Deformation of an island arc: Rate of moment release and crustal shortening in intraplate Japan determined from seismicity and quaternary fault data, J. Geophys. Res., 87, 6829-6852, 1982.

Yamano, M. and S. Goto, Long-term temperature monitoring in a borehole drilled into the Nojima fault, southwest Japan, The Island Arc, 10, 326$335,2001$.

Zhao, D., S. Horiuchi, and A. Hasegawa, Seismic velocity structure of the crust beneath the Japan islands, Tectonophysics, 212, 289-301, 1992.

Zoback, M. D. and M. L. Zoback, State of stress in the Earth's lithosphere, in International Handbook of Earthquake and Engineering Seismology, Academic Press, Amsterdam, pp. 559-568, 2002.

Y. Iio (e-mail: iio@rcep.dpri.kyoto-u.ac.jp), T. Sagiya, and Y. Kobayashi 